\title{
Significant antitumor response of disseminated glioblastoma to bevacizumab resulting in long-term clinical remission in a patient with encephalocraniocutaneous lipomatosis: A case report
}

\author{
RAITA FUKAYA $^{1}$, MASATOKI OZAKI ${ }^{2}$, DAI KAMAMOTO ${ }^{3}$, YUKINA TOKUDA ${ }^{3}$, \\ TOKUHIRO KIMURA ${ }^{4}$, MASAHITO FUKUCHI ${ }^{1}$ and KOJI FUJII ${ }^{1}$
}

\author{
Departments of ${ }^{1}$ Neurosurgery and ${ }^{2}$ Radiation Oncology, Shizuoka City Shimizu Hospital, Shizuoka 424-8636;
}

Departments of ${ }^{3}$ Neurosurgery and ${ }^{4}$ Pathology, Keio University School of Medicine, Tokyo 160-8582, Japan

Received May 6, 2016; Accepted July 7, 2016

DOI: $10.3892 / \mathrm{mco} .2016 .996$

\begin{abstract}
The prognosis of recurrent and disseminated glioblastoma is very poor. Bevacizumab is an effective established therapy for recurrent glioblastoma following treatment with radiotherapy plus temozolomide. However, the efficacy of bevacizumab is limited to prolonging progression-free survival, without significant prolongation of the overall survival. We herein report a case of glioblastoma in a 32-year-old female patient with encephalocraniocutaneous lipomatosis (ECCL) that had disseminated following surgical resection and subsequent treatment with temozolomide and radiation therapy. The disseminated tumors disappeared completely after five courses of bevacizumab therapy. Surprisingly, the patient has remained in clinical remission for $>2.5$ years after dissemination by continuing this therapy. To the best of our knowledge, this is the first case of long-time clinical remission following glioblastoma dissemination and treatment with bevacizumab. In the present case, bevacizumab exerted an atypically strong antitumor effect against disseminated glioblastoma after multidisciplinary treatments had already been applied. Moreover, this is the first report of ECCL associated with a malignant brain tumor.
\end{abstract}

\section{Introduction}

Despite advanced surgery, radiotherapy and chemotherapy, glioblastoma relapses in almost all patient, with tumors recurring locally or in a disseminated pattern. Dissemination, an end-stage complication of glioblastoma, is considered to be untreatable, with a reported mean survival time of

Correspondence to: Dr Raita Fukaya, Department of Neurosurgery, Shizuoka City Shimizu Hospital, 1231 Miyakami, Shimizu-ku, Shizuoka-shi, Shizuoka 424-8636, Japan

E-mail: ritfky0411@yahoo.co.jp

Key words: glioblastoma, encephalocraniocutaneous lipomatosis, bevacizumab, antitumor effect
2-4 months (1-3). Furthermore, previous reports have indicated that chemotherapy for disseminated glioblastoma exhibits limited therapeutic efficacy $(1,3,4)$. Bevacizumab, a monoclonal antibody that inhibits vascular endothelial growth factor, is an effective established therapy for recurrent glioma, following treatment with radiotherapy plus temozolomide. However, there has been no previous report of the effectiveness of bevacizumab in disseminated glioblastoma following multidisciplinary therapy.

Encephalocraniocutaneous lipomatosis (ECCL) is a rare, sporadically occurring neurocutaneous syndrome characterized by the presence of skin lesions and ocular and central nervous system (CNS) anomalies (5). Since Haberland and Perou reported the first case in 1970, 60 patients have been reported to date $(6,7)$, and the etiology of ECCL remains unknown thus far. Although CNS abnormalities, such as intracranial lipomas and arachnoid cysts, are one of the major characteristics of ECCL, the association of ECCL with a malignant brain tumor has never been reported. We herein report a primary glioblastoma in an adult ECCL patient who exhibited an intense and favorable response to bevacizumab.

\section{Case report}

Medical history and diagnosis. A 32-year-old woman was referred to Shizuoka City Shimizu Hospital from a local Children's Hospital at the age of 15 years. At birth, the patient exhibited multiple malformations, including alopecia with underlying fatty tissue on her right frontal scalp, choristoma on her right eye, and a large head circumference. At the age of 4 months, the patient had been diagnosed with hydrocephalus, an intracranial arachnoid cyst and lipoma, all of which were identified during brain imaging performed at the Children's Hospital.

Pathology and surgeries. For her first surgery, the patient underwent a right frontotemporal craniotomy with fenestration of the arachnoid cyst and placement of a ventriculoperitoneal shunt. Although the patient displayed the typical characteristics of ECCL at birth (Fig. 1), she was diagnosed with Goldenhar syndrome, a similar congenital disease characterized by spinal 

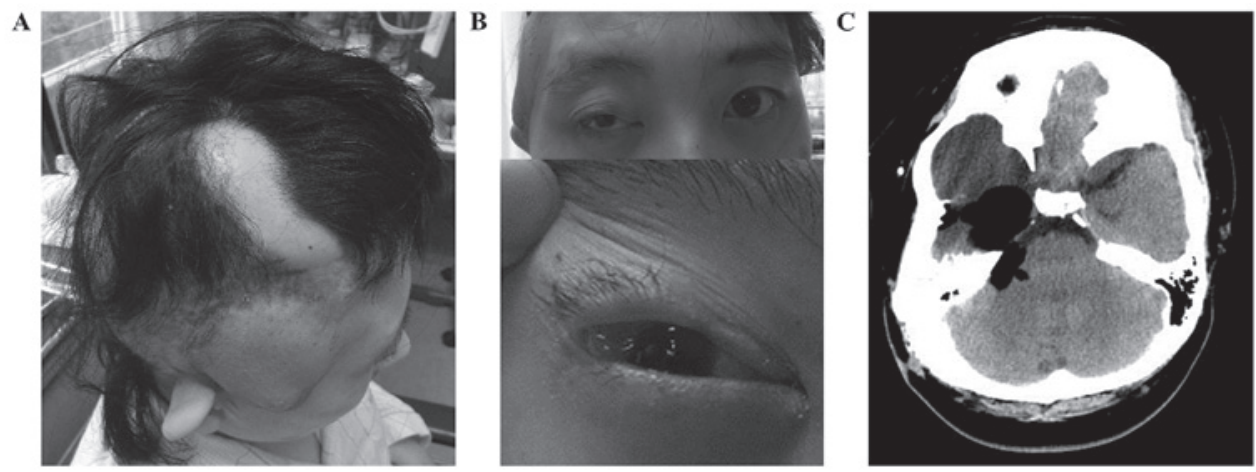

Figure 1. Typical characteristics of encephalocraniocutaneous lipomatosis were observed on the right side of the patient: (A) A smooth, hairless fatty tissue naevus of the scalp, referred to as naevus psiloliparus, was observed on the right frontal scalp. (B) A choristoma was observed in the right conjunctiva. (C) An intracranial lipoma and arachnoid cyst were observed extending from the right middle to the posterior cranial fossa.
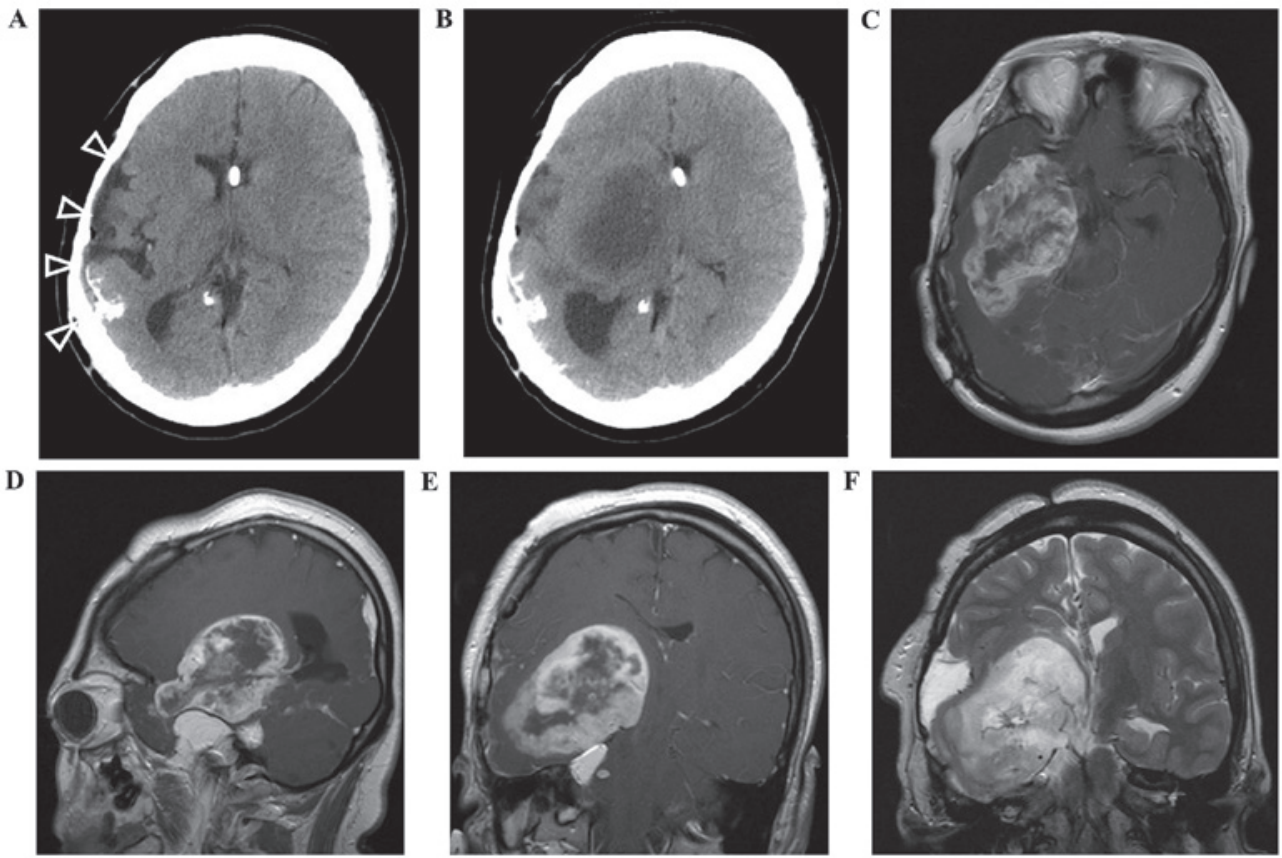

Figure 2. Computed tomography (CT) and magnetic resonance imaging (MRI) scans of the tumor. (A) No tumor was observed on a CT scan performed $\sim 1$ year prior to onset. Atrophy and calcification (arrowheads) in the right hemisphere, which are a common characteristic of encephalocraniocutaneous lipomatosis, are visible. (B) A low-density mass was observed in the right basal ganglia on a CT scan performed at the time of onset. (C-E) Gadolinium-enhanced MRI revealed a ring-enhanced tumor extending from the right temporal lobe to the basal ganglia adjacent to the intracranial lipoma. (F) A small amount of perifocal edema was present in the vicinity of the tumor.

and craniofacial abnormalities during early childhood. The patient was referred to our institution for the consecutive treatment of hydrocephalus and convulsions at the age of 15 years and underwent revision of the ventriculoperitoneal shunt several times at the Children's Hospital and at our institution.

At the age of 32 years, the patient developed a gait disturbance and mild left hemiparesis; these symptoms gradually worsened. A head computed tomography (CT) scan revealed a low-density expanded lesion located at the right temporal lobe extending throughout the right basal ganglia, although no mass lesions were observed on a previous CT conducted 1 year prior (Fig. 2A and B). Brain gadolinium-enhanced magnetic resonance imaging (MRI) revealed a ring-enhanced mass adjacent to the upper surface of the lipoma at the right middle cranial fossa (Fig. 2C-E). Although the mass was large (maximum diameter, $8.0 \mathrm{~cm}$ ), a small amount of perifocal edema was observed (Fig. 2F). A cerebral angiography was performed, demonstrating an arteriovenous shunt and strong tumor staining. The tumor was preoperatively diagnosed as glioblastoma, and the patient underwent a second right frontotemporal craniotomy with partial removal of the tumor. The surgery was performed with the assistance of a navigation system (StealthStation S7 ${ }^{\circledR}$; Medtronic, Minneapolis, MN). The tumor was highly hemorrhagic, and a small portion of the upper dorsal mass of the gadolinium-enhanced lesion remained (Fig. 3).

Postoperative results and additional treatment. A postoperative MRI examination revealed a cerebral infarction located in the right anterior limb of the internal capsule and basal ganglia. No consciousness disorder was observed, and the left lower extremity palsy improved to the point of independent 

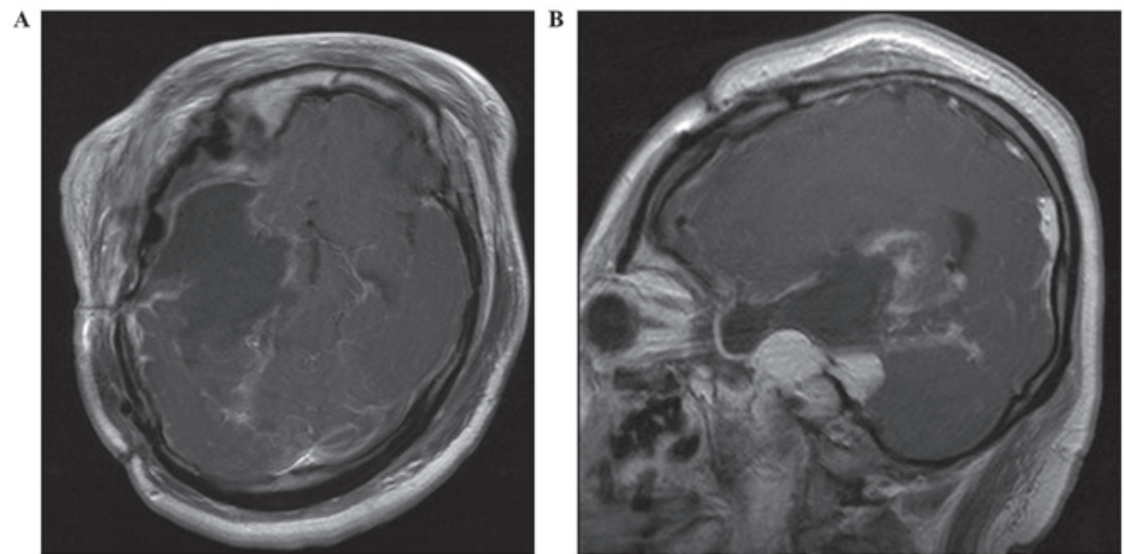

Figure 3. Gadolinium-enhanced magnetic resonance imaging scan of the patient performed 1 day after surgical resection. The gadolinium-enhanced tumor has been partially removed. The residual tumor is visible as an upper dorsal lesion of the tumor. (A) Axial plane and (B) sagittal plane.
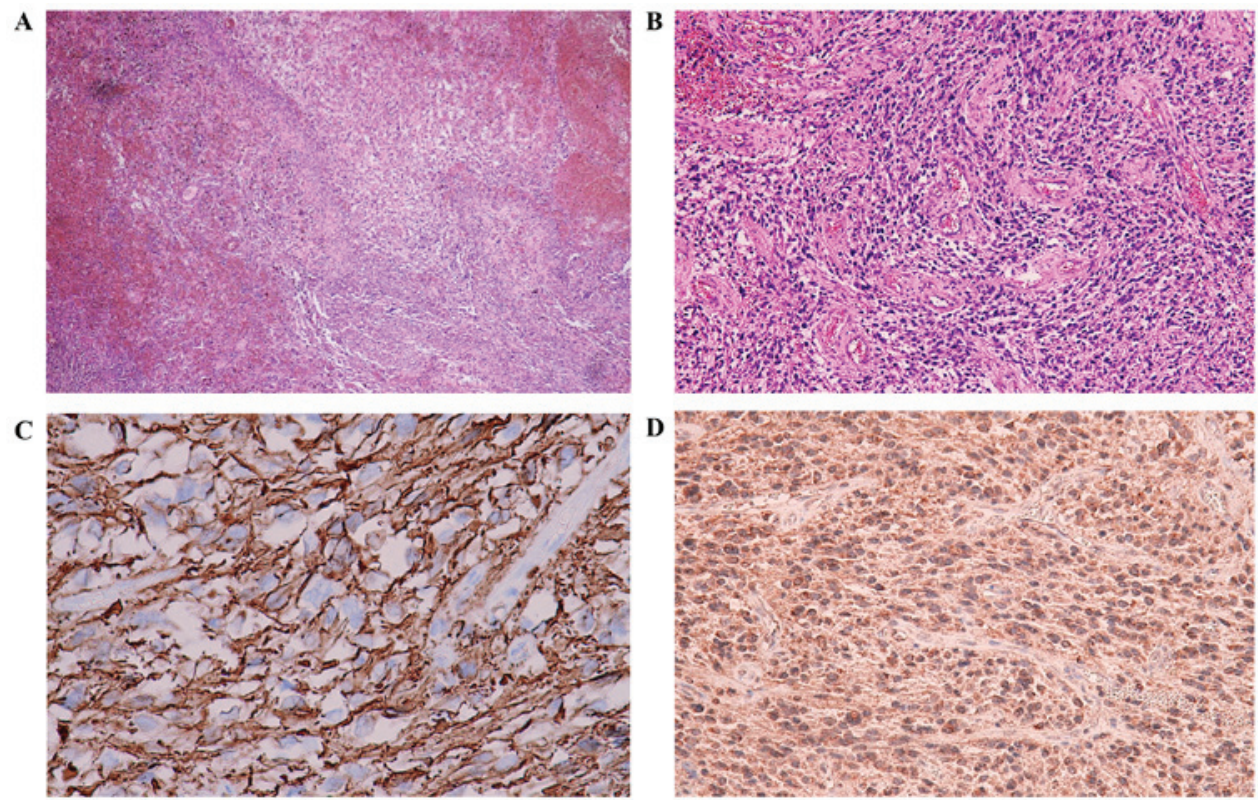

Figure 4. Histology of the tumor. (A) The tumor exhibited pseudopalisading necrosis [hematoxylin and eosin (H\&E) staining; magnification, x100] (B) Abundant microvascular proliferation was observed in the tumor (H\&E staining; magnification, x200). (C) The tumor cells were positive for glial fibrillary acidic protein immunostaining (magnification, $\mathrm{x} 400$ ). (D) The majority of the tumor cells were positive for vascular endothelial growth factor immunostaining (magnification, $\mathrm{x} 200$ ).

gait, whereas the left upper extremity palsy deteriorated. The histological diagnosis of the tumor was glioblastoma (Fig. 4). After the operation, the patient's condition was diagnosed as ECCL based on its characteristic features. At 3 weeks post-resection, local radiotherapy (72 Gy in 60 fractions over 6 weeks) and temozolomide chemotherapy $\left(75 \mathrm{mg} / \mathrm{m}^{2} /\right.$ day $)$ were initiated. An adjuvant chemotherapy regimen was next initiated, consisting of temozolomide at $150 \mathrm{mg} / \mathrm{m}^{2}$ daily for $5 / 28$ days at our outpatient clinic. After six courses of the adjuvant chemotherapy and 8 months after the resection, the patient complained of occasional headaches. A tumor recurrence at the anteromedial wall of the resected cavity and a disseminated tumor located in the cerebellum were confirmed on MRI examination (Fig. 5A and B). Additional chemotherapy with bevacizumab was initiated (10 mg/kg every 2 weeks), concomitantly with temozolomide. The headaches resolved immediately after the initiation of bevacizumab chemotherapy.
After five courses of bevacizumab chemotherapy, another MRI examination revealed that the residual, relapsed and disseminated tumors had completely disappeared. Temozolomide and bevacizumab chemotherapy has now been continued for 2.5 years. The tumor has not recurred, and there have been no complications (Fig. 5C and D). Written informed consent was obtained for the patient for the publication of the case details.

\section{Discussion}

ECCL is a rare neurocutaneous disorder involving multiple organ systems, which typically manifests unilaterally $(5,6)$. To the best of our knowledge, only 3 cases of brain tumors, which were fairly different from the present case, have been reported in patients with ECCL to date (Table I) (7-9). Although all the previous cases were benign tumors and had developed during childhood, the tumor in the present case developed in a young 
Table I. Brain tumors in patients with encephalocraniocutaneous lipomatosis.

\begin{tabular}{|c|c|c|c|c|c|c|}
\hline Case & $\begin{array}{l}\text { Age, } \\
\text { years }\end{array}$ & Gender & $\begin{array}{l}\text { Location of } \\
\text { brain tumor }\end{array}$ & $\begin{array}{l}\text { Pathological } \\
\text { diagnosis }\end{array}$ & $\begin{array}{c}\text { Location of } \\
\text { other abnormalities }\end{array}$ & Refs. \\
\hline 1 & 3 & Male & $\begin{array}{l}\text { Suprasellar } \\
\text { (midline) }\end{array}$ & $\begin{array}{l}\text { Pilocytic } \\
\text { astrocytoma }\end{array}$ & $\begin{array}{l}\text { Coloboma (left eye), } \\
\text { alopecia (occipital scalp) }\end{array}$ & (8) \\
\hline 2 & 7 & Female & $\begin{array}{l}\text { Floor of the third } \\
\text { ventricle (midline) }\end{array}$ & $\begin{array}{l}\text { Papillary } \\
\text { glioneuronal tumor }\end{array}$ & $\begin{array}{l}\text { Choristoma (left eye), } \\
\text { alopecia (right scalp), } \\
\text { arachnoid cyst } \\
\text { (left middle fossa) }\end{array}$ & (9) \\
\hline 3 & 12 & Female & $\begin{array}{l}\text { Left internal } \\
\text { capsule }\end{array}$ & Pilocytic astrocytoma & $\begin{array}{l}\text { Intradermic nodes (right } \\
\text { eye), alopecia (right scalp), } \\
\text { arachnoid cyst (right } \\
\text { middle fossa) }\end{array}$ & (7) \\
\hline 4 & 32 & Female & Right temporal lobe & Glioblastoma & $\begin{array}{l}\text { Choristoma (right eye), } \\
\text { alopecia (right scalp), } \\
\text { intracranial lipoma } \\
\text { (right middle fossa) }\end{array}$ & $\begin{array}{l}\text { Present } \\
\text { study }\end{array}$ \\
\hline
\end{tabular}
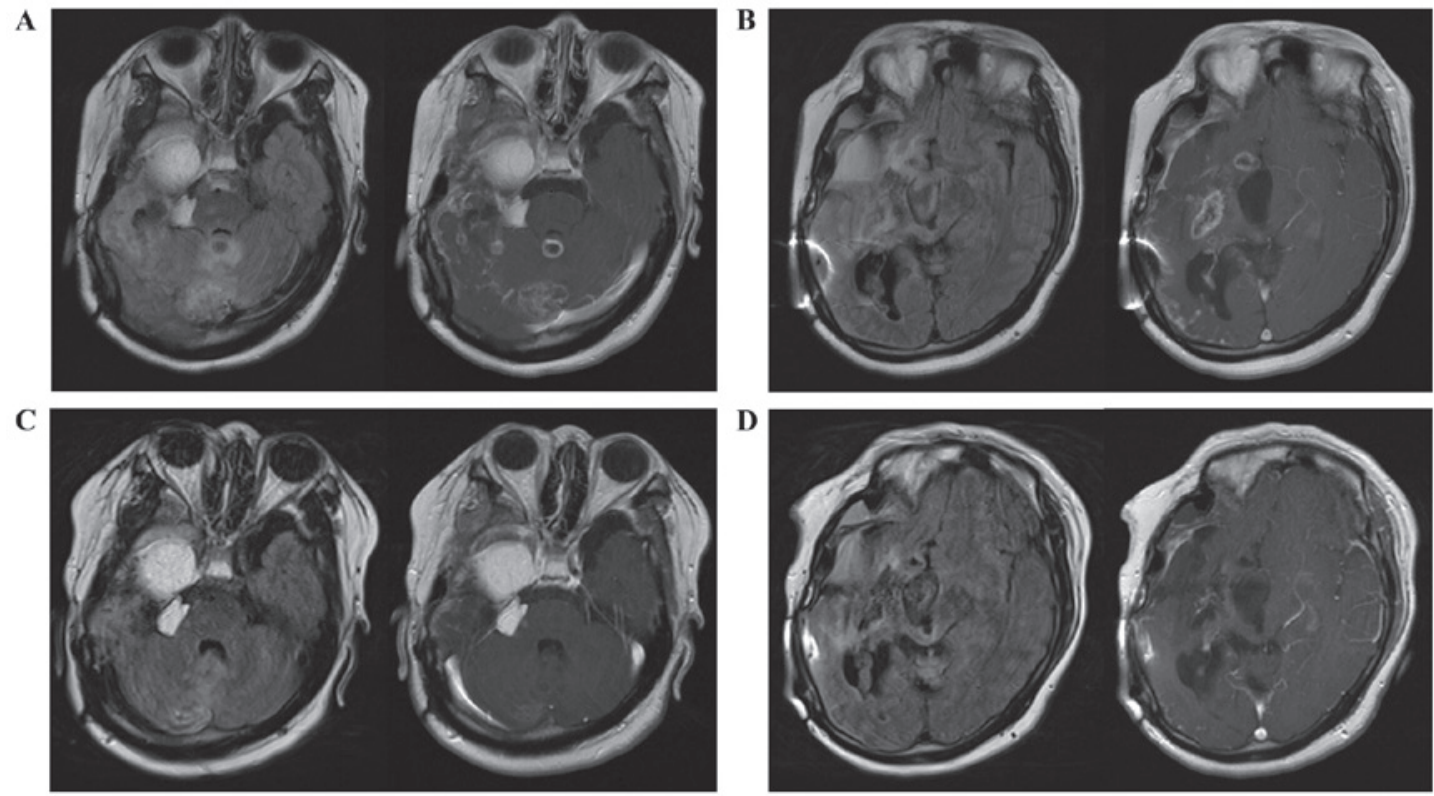

Figure 5. Fluid-attenuated inversion recovery and gadolinium-enhanced magnetic resonance imaging (MRI) demonstrated the disappearance of the disseminated and recurrent tumors following bevacizumab therapy. (A and B) MRI examinations revealed the dissemination and recurrence of the tumor 8 months after surgical resection. (C and D) No recurrent tumor was identified 2.5 years after the initiation of bevacizumab therapy.

adult woman, and the diagnosis of glioblastoma was histologically confirmed. Of note, all the abnormalities, including the brain tumor, were located ipsilaterally in the present case, whereas the tumors had occurred in the midline or on the contralateral side from the other disorders in the previous cases. This evidence strongly indicates that the glioblastoma arose on the biological background of ECCL in this case.

Bevacizumab has recently been administered to patients with anaplastic astrocytoma or glioblastoma and has resulted in prolonged progression-free survival, but has not been successful in prolonging overall survival (10). The reduction of perifocal edema without any antitumor effects has been considered as the main effect of bevacizumab (11). However, in the present case, the recurrent and disseminated tumors disappeared and have not recurred for 2.5 years after the addition of bevacizumab therapy, thus demonstrating a strong antitumor effect in this patient. Glioblastomas are classified as the final form of malignant astrocytic tumors of different etiologies. Several differences, including age at onset, the minimal presence of perifocal edema, and a strong antitumor response to bevacizumab, were observed between this case and 'typical' glioblastomas. These results suggest that the present case was an uncommon type of glioblastoma associated with ECCL. Both ECCL and glioblastoma are rare diseases, so their association in our case is unlikely to be a coincidence. The reason for the atypically strong antitumor effect of bevacizumab 
in this case remains unknown. The biological differences between this particular glioblastoma in our ECCL patient and common glioblastomas remain unknown, as this is the first case of ECCL coexisting with a glioblastoma. Further clinical information regarding the genetic background of ECCL may contribute to the investigation of glioblastoma therapy.

In summary, to the best of our knowledge, this is the first case with a confirmed significant response and long-term clinical remission in a patient with disseminated glioblastoma who received bevacizumab therapy. This case is also the first report of ECCL in association with glioblastoma.

\section{References}

1. Arita N, Taneda M and Hayakawa T: Leptomeningeal dissemination of malignant gliomas. Incidence, diagnosis and outcome. Acta Neurochir (Wien) 126: 84-92, 1994.

2. Awad I, Bay JW and Rogers L: Leptomeningeal metastasis from supratentorial malignant gliomas. Neurosurgery 19: 247-251, 1986.

3. Greenberg AD, Scatliff JH, Selker RG and Marshall MD: Spinal cord metastasis from bronchogenic carcinoma. A case report. J Neurosurg 23: 72-75, 1965.

4. Delattre JY, Walker RW and Rosenblum MK: Leptomeningeal gliomatosis with spinal cord or cauda equina compression: A complication of supratentorial gliomas in adults. Acta Neurol Scand 79: 133-139, 1989.
5. Moog U: Encephalocraniocutaneous lipomatosis. J Med Genet 46: 721-729, 2009.

6. Haberland C and Perou M: Encephalocraniocutaneous lipomatosis. A new example of ectomesodermal dysgenesis. Arch Neurol 22: 144-155, 1970 .

7. Valera ET, Brassesco MS, Scrideli CA, de Castro Barros MV, Santos AC, Oliveira RS, Machado HR and Tone LG: Are patients with encephalocraniocutaneous lipomatosis at increased risk of developing low-grade gliomas? Childs Nerv Syst 28: 19-22, 2012.

8. Brassesco MS, Valera ET, Becker AP, Castro-Gamero AM, de Aboim Machado A, Santos AC, Scrideli CA, Oliveira RS, Machado HR and Tone LG: Low-grade astrocytoma in a child with encephalocraniocutaneous lipomatosis. J Neurooncol 96: 437-441, 2010.

9. Phi JH, Park SH, Chae JH, Wang KC, Cho BK and Kim SK: Papillary glioneuronal tumor present in a patient with encephalocraniocutaneous lipomatosis: Case report. Neurosurgery 67: E1165-E1169, 2010.

10. Chinot OL, Wick W, Mason W, Henriksson R, Saran F, Nishikawa R, Carpentier AF, Hoang-Xuan K, Kavan P, Cernea D, et al: Bevacizumab plus radiotherapy-temozolomide for newly diagnosed glioblastoma. N Engl J Med 370: 709-722, 2014.

11. Narayana A, Gruber D, Kunnakkat S, Golfinos JG, Parker E, Raza S, Zagzag D, Eagan P and Gruber ML: A clinical trial of bevacizumab, temozolomide, and radiation for newly diagnosed glioblastoma. J Neurosurg 116: 341-345, 2012. 